\title{
BMJ Open Medication double-checking procedures in clinical practice: a cross-sectional survey of oncology nurses' experiences
}

\author{
D L B Schwappach, ${ }^{1,2}$ Yvonne Pfeiffer, ${ }^{1}$ Katja Taxis ${ }^{3}$
}

To cite: Schwappach DLB, Pfeiffer Y, Taxis K. Medication double-checking procedures in clinical practice: a cross-sectional survey of oncology nurses' experiences. BMJ Open 2016:6:e011394. doi:10.1136/bmjopen-2016011394

- Prepublication history for this paper is available online. To view these files please visit the journal online (http://dx.doi.org/10.1136/ bmjopen-2016-011394).

Received 4 February 2016 Revised 17 May 2016 Accepted 25 May 2016

\section{CrossMark}

\author{
${ }^{1}$ Swiss Patient Safety \\ Foundation, Zuerich, \\ Switzerland \\ ${ }^{2}$ Institute of Social and \\ Preventive Medicine (ISPM), \\ University of Bern, Bern, \\ Switzerland \\ ${ }^{3}$ Department of Pharmacy, \\ Unit of Pharmacotherapy and \\ Pharmaceutical Care \\ University of Groningen, \\ Groningen, The Netherlands
}

Correspondence to Dr David Schwappach; schwappach@ patientensicherheit.ch

\section{ABSTRACT}

Background: Double-checking is widely recommended as an essential method to prevent medication errors. However, prior research has shown that the concept of double-checking is not clearly defined, and that little is known about actual practice in oncology, for example, what kind of checking procedures are applied.

Objective: To study the practice of different doublechecking procedures in chemotherapy administration and to explore nurses' experiences, for example, how often they actually find errors using a certain procedure. General evaluations regarding doublechecking, for example, frequency of interruptions during and caused by a check, or what is regarded as its essential feature was assessed.

Methods: In a cross-sectional survey, qualified nurses working in oncology departments of 3 hospitals were asked to rate 5 different scenarios of double-checking procedures regarding dimensions such as frequency of use in practice and appropriateness to prevent medication errors; they were also asked general questions about double-checking.

Results: Overall, 274 nurses (70\% response rate) participated in the survey. The procedure of jointly double-checking (read-read back) was most commonly used ( $69 \%$ of respondents) and rated as very appropriate to prevent medication errors. Jointly checking medication was seen as the essential characteristic of double-checking - more frequently than 'carrying out checks independently' ( $54 \%$ vs $24 \%$ ). Most nurses $(78 \%)$ found the frequency of double-checking in their department appropriate. Being interrupted in one's own current activity for supporting a double-check was reported to occur frequently. Regression analysis revealed a strong preference towards checks that are currently implemented at the responders' workplace. Conclusions: Double-checking is well regarded by oncology nurses as a procedure to help prevent errors, with jointly checking being used most frequently. Our results show that the notion of independent checking needs to be transferred more actively into clinical practice. The high frequency of reported interruptions during and caused by double-checks is of concern.

\section{INTRODUCTION}

Medication errors pose a serious threat to patients with cancer. ${ }^{1-5}$ Walsh et al ${ }^{6}$ reported that among visits by adult patients with
Strengths and limitations of this study

- This is the first investigation into doublechecking procedures and common violations in cancer care.

- We provide evidence that the value of doublechecking procedures as perceived by nurses is attributed to the joint action rather than the independence of checks and thus does not match current recommendations claiming that checks need to be carried out independently to increase safety.

- The survey response rate is satisfactory and the sample includes nurses from three large hospitals. However, results may be subject to bias due to the self-reported nature of the data.

cancer, $7.1 \%$ of medications were associated with a medication error with more than half of all errors occurring during administration. Although not all medication errors are harmful, consequences can be serious or disastrous, especially in patients with cancer. Strategies that have been recommended to improve patient safety in oncology include electronic prescribing, standardisation of processes and order forms, shifting medication-related tasks to clinical pharmacists and use of checklists for safe administration of drugs. ${ }^{7-11}$ Double-checking (DC) of medication is the safety intervention frequently called for, especially to prevent administration errors. The Institute for Safe Medication Practices (ISMP) recommends the implementation of the double-check, but judiciously, and in a standardised process. ${ }^{12}$ The ISMP also points to the importance of independence of checking procedures where the first professional does not communicate the results to expect to the second professional. The UK National Patient Safety Agency recommends healthcare organisations to "use DC systems such as an independent check by another practitioner, and dose checking software in 'Smart' infusion pumps and syringe drivers'. ${ }^{13}$ DC can be defined as a procedure that requires two 
qualified health professionals, usually nurses, checking the medication before administration to the patient. DC is a redundant function based on the subjective theory that human errors can be minimised by other individuals' compensatory behaviour. ${ }^{14}$ The strategy is borrowed from system engineering where redundancy is used to achieve safety and reliability in technical systems. In broad terms, redundancy means that a system component (eg, mass storage) is duplicated and serves as a back-up in case of failure. Redundancy as a design strategy for healthcare systems has been discussed by Tamuz and Harrison ${ }^{15}$ in the context of high-reliability theory and normal accident theory. Despite the proliferation of the procedure and its ad hoc plausibility, there is a paucity of research into the effectiveness of DC to either support or refute this practice. ${ }^{16}$ In this context, it is important to note that DC medication administrations is a time-consuming and thus resource-intensive process. ${ }^{17-19}$

There is widespread support for DC, but most recommendations and guidelines lack details on what constitutes a double-check and how it should be performed. In practice, various forms of DC procedures are implemented including, for example, a single person conducting the same check twice; a second person verifying the check of the first professional (do-and-show check); a single person checking against some form of computerised support (eg, calculations performed by an infusion pump); two professionals checking independently of each other, and sequentially or together (eg, readread back). Owing to such variability in DC processes, it is not surprising that there are reports about confusion and misconceptions among healthcare professionals. ${ }^{20} 21$ In a recent qualitative study in Canada, DC was inconsistently conceptualised among healthcare professionals with a variety of ambiguous but 'taken as understood' meanings attached to it. ${ }^{21}$ Nurses at many departments today perform countless single and double drug verifications, often under inadequate working conditions (eg, insufficient light, space, noise) and without any compensation for the time needed to perform these checks. Often, these checks are done superficially ${ }^{22}$ and 'true independence' of checks-the central feature for successful error detection-is hard to achieve in practice. Non-independent checks are prone to confirmation bias and their value is thus uncertain. Violations of DC procedures are frequent, probably due to the workload and lack of standardisation. ${ }^{22}{ }^{23}$ Furthermore, DC itself can negatively impact safety by causing a considerable number of additional interruptions in workflow. Finally, diffusion of responsibility can lead to a false sense of safety through reliance on the following check $^{24}$ and thus increase risk. In qualitative studies, nurses indicated that DC reduced the perceived responsibility of individuals because they trust in the second checking person to find potential mistakes-an effect which is often called 'social loafing'. 2025

In oncology, DC is frequently recommended and claimed as a 'state of the art' procedure. ${ }^{26}{ }^{27}$ The American
Society of Clinical Oncology (ASCO) and the Oncology Nursing Society (ONS) standards for the administration of chemotherapy require that before chemotherapy administration, at least two practitioners (1) verify patient identification using at least two identifiers; (2) confirm with the patient the planned treatment, drug route and symptom management; (3) verify the accuracy of the drug name, dose, volume, rate of and route of administration, expiration dates/times and appearance and physical integrity of the drugs; (4) sign to indicate verification was done. ${ }^{16}$ The Swiss nursing standards on chemotherapy administration are not binding and state that, depending on the institutional policy, a double-check of the drug and the dose should be conducted during preparation and administration. ${ }^{28}$ There is, however, neither a definition of a robust checking procedure given in the document nor recommendations proposed on how DC should exactly be performed.

Despite its wide diffusion, very little is known about DC practices in cancer care. This study addresses this gap using a cross-sectional survey among oncology nurses. The main aim of our study was to describe practice patterns (types, frequencies and independence of checks performed) and oncology nurses' experiences with the double-check in chemotherapy administration.

Our primary research question was to assess which specific DC routines are implemented and what the experiences with them are. We examined what constitutes a 'good double-check' for cancer nurses, how frequently procedures are violated, which barriers nurses perceive in conducting DC in practice, and whether they would prefer an expansion or a reduction of DC procedures.

Our secondary research question was to investigate nurses' judgements about the appropriateness of the various different DC procedures in discovering medication errors and the factors affecting their evaluations. We hypothesised that nurses have clear judgements on the value of different $\mathrm{DC}$ routines based on their prior experiences and their professional expertise. Understanding nurses' assessments of suitability of DC procedures is crucial for implementing any changes to current DC practices and for developing a consistent conceptualisation of DC.

A further secondary research question was to determine if there were differences in DC practices between inpatient and outpatient care. Since clinical processes and working conditions (eg, patient flow and throughput, staffing, etc) often differ considerably between wards and ambulatory infusion units, we assumed that this may also impact how double-checks are performed and perceived. Knowledge about these differences would be useful for designing DC procedures and policies that are adapted to the specific setting and context.

\section{METHODS \\ Sample}

Three hospitals participated with their oncology departments (two university hospitals, one large regional 
hospital). From each hospital, the oncology wards and ambulatory units took part. All qualified nurses (ie, nursing staff authorised to prepare and administer chemotherapy) working on the participating units received the survey together with a prepaid envelope and a chocolate bar. Return of the survey was considered as implied informed consent. Our study does not involve interventions, no health-related data or biological material are being analysed, the data were completely anonymised and approached individuals could easily refuse participation by not returning the survey.

\section{Survey}

\section{Development}

The survey was developed by the investigators based on the literature, consultations with experts and clinical staff, and initial field observations. The main challenge in developing the survey was the inconsistent, vague and variable concepts held by nurse clinicians and the various procedures implemented in practice. It became obvious that simply asking details about the doublecheck' would result in non-interpretable data due to non-standardised use of the term. Therefore, we assessed which checking procedures are performed in practice during initial field observations. One author visited all participating units and observed DC practices to gain an understanding of the different forms of DC procedures implemented. In informal conversations during and after observation, nurses were asked about the procedures in a non-judgemental manner until the core steps, their sequence, the actions and interactions between staff were clear for each scenario. The initial observations also gave insights into common rules embedded in checking procedures (which are not necessarily written down anywhere). For example, medications should be administered by a nurse involved in the DC and not by a third person, and double-checks should not be carried out in series for the medications of several patients. Finally, the field observations were also useful to collect information about the environmental conditions under which DC is performed (eg, rooms, light, noise). On the basis of the observations, we developed (1) a set of scenarios describing certain procedures and (2) survey questions that were asked for every kind of scenario in order to be able to compare the scenarios.

Six experts from nursing, oncology, clinical pharmacy and hospital risk management gave feedback on a survey draft. The survey was pretested for clarity and wording in a sample of $n=39$ health care workers (HCW) from two hospitals not participating in the main study. Only minor adjustments were made.

\section{Survey instrument}

The survey consisted of two main sections: In the first section (reported here), we used scenarios describing DC procedures implemented in clinical practice and asked responders to rate these scenarios regarding various aspects. This allowed us to assess practice patterns, experiences with different DC procedures and clinicians' judgements of the effectiveness of DC procedures in discovering medication errors. We used these scenarios of different DC procedures to obtain detailed evaluations and to avoid the loosely and inconsistently defined 'umbrella concept' of DC. In this section, we also asked some general items related to DC, for example, regarding unit policy or perception of essential elements of DC. The second survey part (not reported herein) assessed norms and beliefs in DC effectiveness for medication safety.

\section{DC scenarios and related survey items}

In the field observations, we identified five different core DC procedures implemented in practice. For each of them, we developed a brief description and an illustration of the main steps (scenarios A-E, see figures 1 and 2). Each participant responded to all scenarios and was asked the same set of questions for each scenario:

1. Item 1: how appropriate this type of DC is to prevent medication errors ('appropriateness rating'; 7-point Likert from 'very appropriate' to 'not appropriate at all');

2. Item 2: whether this type of DC is being performed at their unit (yes routinely/only in exceptions/no/ don't know); if yes:

3. Item 3: how many of such double-checks they personally conduct on an average working day, including cytostatics, potassium, antiemetics (none/1-5/6-10/ more than 10);

4. Item 4: how frequently they detect errors, discrepancies or inconsistencies during a double-check of this type (daily or several times daily/weekly or several times weekly/monthly or several times monthly/few times per year/never);

5. Item 5: whether they would eliminate this type of $\mathrm{DC}$, in case they were free to decide for their unit (yes/no keep as is/perform only in exceptions);

6. Item 6, only for scenarios $\mathrm{C}, \mathrm{D}, \mathrm{E}$, which describe counting and calculating: whether the second nurse already knows the results of her colleague when she repeats the procedure (eg, whether she can see the ticket with the number of tablets or the flow rate, etc; yes/no).

\section{Generalised items}

Participants were then asked to complete a number of generalised items: they were asked to indicate the existence of guidelines for DC at their unit; essential elements of a good double-check; number of doublechecks at their unit; the frequency of violations of DC procedures (see table 3 for details); frequency of interruptions caused by DC and conditions interfering with performing a good double-check; practice and preferences towards the DC of premedications (drugs given prior to chemotherapy to prevent side effects of 


Scenario A Verification of order and IV bag:
Nurse A reads out loud data on the order (paper or computer screen). Nurse B verifies
against the IV bag and confirms. Nurse B reads out loud data on the IV bag label and Nurse
A confirms against the order. One of both administers the medication to the patient.
Scenario B Verification of order and IV bag:
Nurse A verifies data on IV bag label against the order (paper or computer screen). Later
nurse B verifies data on IV bag label against the order (paper or computer screen) again. One
of both administers the medication to the patient.
Scenario C Local on-site preparation of infusions:
Based on the order, nurse A assembles drugs and solvents, calculates flow-rate and volume
and writes down the results on labels. Nurse B verifies drugs and solvents against the order,
repeats the calculations and confirms. One person prepares the infusions. Nurse A or B
administers the medication to the patient.
Scenario D Calculation of flow-rate for infusions:
Nurse A calculates the flow-rate for the infusion and writes down the result. Nurse B repeats
the calculation. She compares both results and confirms. One of both administers the
medication to the patient.
Scenario E Calculation and preparation of oral chemotherapies:
Nurse A calculates the number of tablets against the order and prepares them. Nurse B
repeats the calculation and verifies the prepared tablets. One of both dispenses the
medication to the patient.

Figure 1 Double-checking scenarios and descriptions provided in the survey.

treatment, eg, antiemetic drugs and steroids); and recent experience of severe medication errors. Finally, respondents completed a few sociodemographic and work-related items.

\section{Analysis}

Survey responses were descriptively analysed. Owing to item-level missing data, the sample size varies slightly per item. $\chi^{2}$ tests were conducted to identify group differences between wards and ambulatory infusion units. In order to test for differences in nurses' appropriateness ratings (item 1 listed above) between DC scenarios, analysis of variance (ANOVA) was used.

To answer our secondary research question, that is, determine predictors for the appropriateness ratings (item 1 listed above), logistic regression analysis was conducted. Since each responder evaluated five scenarios, the unit of analysis in this regression model was the judgement provided in response to the scenarios, and not the individual respondent. The sample size for this analysis is thus $n=$ number of responders $\times$ number of rated scenarios. The dependent variable (appropriateness rating, item 1 listed above) was dichotomised with values $1-4=$ not appropriate and values 5-7=appropriate. Type of DC procedure evaluated (scenarios A-E), current implementation of this DC procedure at the unit, and perceived essential element of a good doublecheck were included as predictors (independent variables). With this analysis, we assess the impact of nurses' current DC practices at their workplace on their ratings
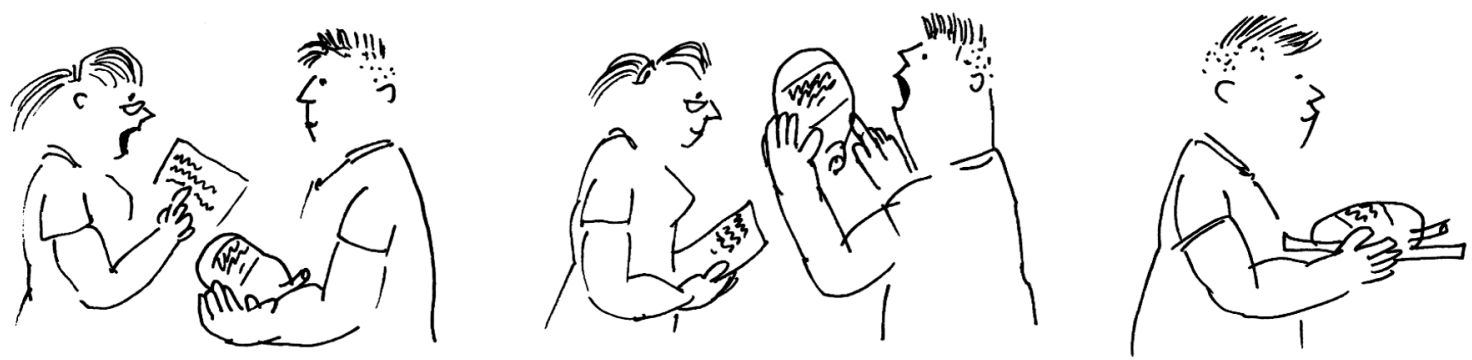

Figure 2 Illustration of double-checking procedure A provided in the survey. 
of appropriateness of the distinct DC procedures. In other words, we correct DC appropriateness ratings for a bias towards 'current practice'. Personal and workrelated characteristics were included to adjust the appropriateness ratings. We used cluster robust SEs to relax the assumption of independence of observations within individuals. All tests were two-sided and a $\mathrm{p}$ value $<0.05$ was considered significant.

\section{RESULTS}

Of the 389 distributed surveys, 274 were completed and returned (response rate $=70 \%$ ). Sample details are provided in table 1 . The majority of responders were experienced nurses working on wards for at least 25 hours per week in direct patient care. The majority of nurses $(80 \%)$ reported that there were internal guidelines explaining which checks were required for which medications and that they knew them well. Knowing that such guidelines existed but not knowing their contents well was reported by $11 \%$. The remainder were not aware of guidelines for their unit. Overall, 68 responders $(25 \%)$ reported that one or more serious medication errors had taken place in their unit during the past 12 months. Of those, the majority $(68 \%)$ believed that the last serious

\begin{tabular}{|c|c|c|}
\hline \multirow[b]{2}{*}{ Characteristic } & \multicolumn{2}{|c|}{ Responders } \\
\hline & $\mathbf{n}$ & Per cent \\
\hline Female gender & 240 & 91 \\
\hline Age, mean (SD), years & 37 & \\
\hline $18-25$ & 31 & 12 \\
\hline $26-40$ & 149 & 56 \\
\hline $41-55$ & 67 & 25 \\
\hline $56-65$ & 17 & 6 \\
\hline \multicolumn{3}{|l|}{ Qualification* } \\
\hline Qualified nurse & 205 & 76 \\
\hline Oncology nursing expert & 42 & 16 \\
\hline Head nurse & 17 & 6 \\
\hline Other & 4 & 1 \\
\hline \multicolumn{3}{|l|}{ Primary place of work } \\
\hline Ward/oncology day care unit & 220 & 82 \\
\hline Ambulatory infusion unit & 48 & 18 \\
\hline \multicolumn{3}{|c|}{ Weekly hours in direct patient care (hours/week) } \\
\hline$<10$ & 14 & 5 \\
\hline 10 to 25 & 60 & 23 \\
\hline 25 to 40 & 123 & 47 \\
\hline$>40$ & 67 & 25 \\
\hline $\begin{array}{l}\text { Experience with barcode scanning } \\
\text { (eg, blood products) }\end{array}$ & 123 & 46 \\
\hline $\begin{array}{l}\text { Preparation of cytostatics at unit } \\
\text { Years of practice in oncology }\end{array}$ & Years of practice in oncology & 31 \\
\hline$<1$ & 25 & 10 \\
\hline 1 to 5 & 89 & 36 \\
\hline 5 to 10 & 55 & 22 \\
\hline$>10$ & 79 & 32 \\
\hline
\end{tabular}

error could have been prevented with a thorough double-check.

\section{Practice patterns and experiences with DC procedures}

Table 2 reports practice patterns and experiences with the different DC scenarios. 'read-read back' of orders and infusion bag labels (scenario A) was the most widely implemented DC procedure. A repetitive single check of order and infusion bag (scenario B) was least common. Within each type of DC scenario, the largest fraction of responders was involved in 1-5 checks per average working day. Nurses working on ambulatory units were involved in significant higher frequencies of doublechecks. Summarised across the different DC procedures, $48 \%$ of all frequency ratings provided by ambulatory nurses indicate performance of $>5$ checks per day versus $15 \%$ of these ratings reported by nurses on ward $(p<0.001)$. The reported frequency with which DC procedures detected errors and inconsistencies varied considerably. Approximately a fifth of nurses practising procedures B (repetitive single check) and C (repetitive single check of order, calculations and drugs for preparation) reported that these checks detected inconsistencies at least several times a week. In contrast, the more widely implemented DC procedures were reported to detect inconsistencies with a much lower frequency. Only between $37 \%$ (scenario $\mathrm{C}$ ) and $51 \%$ (scenario E) of participants reported that commonly the second nurse did not know the results of her preceding colleague when she repeated a counting or calculating procedure (truly independent check). Across all presented DC procedures, the majority of responders would not eliminate the procedure from their routines (range 73-94\%).

\section{Characteristics of the double-check and violations}

Participants were clearly discordant on what constitutes the essential characteristic of a good double-check: 'two persons check the medication together' was selected as the main feature by 54\%; 'two persons make the same checks successively' was selected by $22 \%$ of responders and $24 \%$ answered that 'one person independently repeats a process (eg, counting) without knowing the results of her preceding colleague' was the crucial characteristic of a good double-check. There were no significant differences in evaluations of the main feature of a good double-check between nurses working on wards or at ambulatory units. Nurses reported different types of violations of medication safety rules related to DC with varying levels of frequency (table 3): Performing the double-check for medications of several patients in series-without a break and without completing the drug administration before starting the double-check for the next patient-was the most commonly reported deviation from safe DC rules. Of responders, 36\% reported any of the three types of violations to happen at least several times per week at their unit (ambulatory infusion unit: $46 \%$; ward $=32 \%, \mathrm{p}=0.074$ ). 
Table 2 Practice patterns and experiences with different double-checking (DC) procedures (scenarios; for item wordings, see Methods section)

\begin{tabular}{|c|c|c|c|c|c|}
\hline & \multicolumn{5}{|c|}{ DC procedure, n (\% within DC procedure) } \\
\hline & $\overline{\mathbf{A}}$ & B & C & D & $E$ \\
\hline \multicolumn{6}{|c|}{ Type of DC performed at unit (item 2) } \\
\hline Routinely & $185(69)$ & $57(21)$ & $87(33)$ & $117(45)$ & $175(66)$ \\
\hline Exceptionally & $40(15)$ & $34(13)$ & $43(16)$ & $64(24)$ & $8(3)$ \\
\hline Not performed & $45(17)$ & $175(66)$ & $131(50)$ & $81(31)$ & $81(31)$ \\
\hline \multicolumn{6}{|c|}{ Number of double-checks responder is doing on an average day* (item 3) } \\
\hline None & $16(7)$ & $21(23)$ & $20(15)$ & $21(12)$ & $14(8)$ \\
\hline 1 to 5 & $158(70)$ & $40(44)$ & $81(62)$ & $133(74)$ & $138(76)$ \\
\hline 6 to 10 & $36(16)$ & $14(16)$ & $13(10)$ & $14(8)$ & $15(8)$ \\
\hline$>10$ & $15(7)$ & $15(17)$ & $17(13)$ & $11(6)$ & $14(8)$ \\
\hline \multicolumn{6}{|c|}{ DC performed 'truly' independently* (item 6) } \\
\hline Yes & - & - & $47(37)$ & $81(46)$ & $89(51)$ \\
\hline \multicolumn{6}{|c|}{ Frequency of detection of errors/inconsistencies during DC* (item 4) } \\
\hline Never/rarely $\dagger$ & $167(75)$ & $49(55)$ & $72(56)$ & $114(64)$ & $130(72)$ \\
\hline Several per month & $39(17)$ & $23(26)$ & $31(24)$ & $48(27)$ & $37(20)$ \\
\hline Several per week/day $\dagger$ & $18(8)$ & $17(19)$ & $26(20)$ & $17(9)$ & $14(8)$ \\
\hline \multicolumn{6}{|c|}{ Preference to eliminate this type of $\mathrm{DC}^{\star}$ (item 5) } \\
\hline Eliminate completely & 7 (3) & $2(2)$ & $2(2)$ & $5(3)$ & $1(1)$ \\
\hline Do it only in exceptional cases & $23(10)$ & $22(25)$ & $26(20)$ & $30(17)$ & $10(6)$ \\
\hline Keep as is & $194(87)$ & $65(73)$ & $100(78)$ & $144(80)$ & $167(94)$ \\
\hline
\end{tabular}

Number of double-checks at unit

When asked to consider the number of double-checks at their unit, most surveyed nurses regarded the scheduled number of double-checks in their unit as good and appropriate $(78 \%)$. Additional double-checks were favoured by $17 \%$. Only a small minority said that there should be fewer double-checks (5\%). A preference towards additional double-checks was significantly more frequent among responders working on wards compared with ambulatory infusion units $(21 \%$ vs $2 \%, \mathrm{p}=0.005)$. Half of the respondents (49\%) reported that premedications were not double-checked at all at their unit $(19 \%$ routinely and 28\% occasionally). The group of responders was nearly equally split in their preference for or against the DC of premedications: Fifty-five per cent said they would favour and $45 \%$ would opt against a routine DC of all premedications, were they free to decide for their unit. Those who already routinely performed double-checks on premedications were much more likely to support this procedure $(90 \%)$ as compared with those who checked them only occasionally or not at all $(47 \%, \mathrm{OR}=10.43, \mathrm{p}<0.001)$.

\section{Interruptions and barriers for DC performance}

Many nurses reported that they were frequently interrupted in their own tasks to support a colleague doing a double-check: 1-5 interruptions of their current activity per day were reported by $39 \%$; a substantial fraction (20\%) experienced more than 5 interruptions per day. Nurses working at ambulatory infusion units selfreported significantly more interruptions than nurses working on wards ( $40 \%$ vs $16 \%$ reporting more than five interruptions per day, $\mathrm{p}=0.001)$. Almost all of the respondents $(96 \%)$ reported at least one factor which frequently interferes with performing good DC (multiple answers possible): $78 \%$ felt disturbed by hurry and hectic at the unit, $78 \%$ by interruptions and distractions, $58 \%$ by noise and poor illumination in the medication

Table 3 Frequency of self-reported deviations from double-checking (DC) safety rules

\begin{tabular}{|c|c|c|c|c|}
\hline Deviation from DC safety rules & $\begin{array}{l}\text { Several } \\
\text { times daily }\end{array}$ & $\begin{array}{l}\text { Several times } \\
\text { weekly }\end{array}$ & $\begin{array}{l}\text { Several times } \\
\text { monthly }\end{array}$ & $\begin{array}{l}\text { Less frequently } \\
\text { or never }\end{array}$ \\
\hline $\begin{array}{l}\text { How frequently is a scheduled double-check done only } \\
\text { superficially, not completed or not conducted at all? }\end{array}$ & $2(0.7 \%)$ & $16(6 \%)$ & $25(9 \%)$ & $239(84 \%)$ \\
\hline $\begin{array}{l}\text { How frequently does a patient get her medication from } \\
\text { staff who were not involved in the DC of this } \\
\text { medication? }\end{array}$ & $6(2 \%)$ & $27(10 \%)$ & $44(17 \%)$ & $188(71 \%)$ \\
\hline $\begin{array}{l}\text { How frequently are the medications of several patients } \\
\text { double-checked in series without a break? }\end{array}$ & $29(11 \%)$ & $42(16 \%)$ & $54(21 \%)$ & 135 (52\%) \\
\hline
\end{tabular}


room, $53 \%$ by problems in finding a colleague for DC, $29 \%$ by overcrowded rooms and $25 \%$ by their own fatigue.

\section{Appropriateness of DC procedures and its predictors}

Responders evaluated the appropriateness of each of the five DC procedures for preventing medication errors, irrespective of whether they performed this type of check in their daily routines. The differences in the appropriateness ratings between DC procedures were considerable (ANOVA $\mathrm{F}=76.6, \mathrm{p}<0.0001$ ). The ratings were highest for scenarios A (mean=6.0, CI 5.8 to 6.1) and $\mathrm{E}$ (mean=6.0, CI 5.8 to 6.1 ), followed by $\mathrm{D}$ (mean 5.5 , CI 5.3 to 5.7$)$, C (mean=4.9, CI 4.8 to 5.2$)$ and B (mean=3.9, CI 3.7 to 4.2 ). Results of the logistic regression analysis confirm that the appropriateness of the five different DC procedures was judged differently, even after adjusting for other variables (table 4). DC procedures $\mathrm{B}$ and $\mathrm{C}$ were perceived as significantly less useful in preventing medication errors compared with procedures A and E. DC procedures which were implemented at the responder's work environment and thus currently personally experienced scored systematically higher on the appropriateness rating, even after adjusting for the type of check and other variables: procedures nurses were currently using at their unit were more than 17 times more likely to be judged appropriate compared with procedures outside their scope of current experience. The difference between the categories 'not practiced' and 'occasionally practiced' explained, on average, a one-point difference on the response scale. Finally, female gender was the only personal and workrelated variable affecting the perceived benefit of $\mathrm{DC}$ procedures for preventing medication errors. Working on wards or at ambulatory units did not affect appropriateness ratings.

\section{DISCUSSION}

To the best of the authors' knowledge, this is the first analysis of nurses' experiences with and evaluations of different procedures of DC of medication in cancer care. We surveyed experienced oncology nurses from three large hospitals including wards and ambulatory infusion units. The response rate was satisfactory.

\section{Positive experiences and support for DC}

Nurses in our study had positive attitudes towards DC, expressed in the high appropriateness ratings of all checking procedures and the fact that more than half of the respondents would also prefer to extend the doublecheck to premedications. The five described DC procedures were regarded to be of different value with the joint 'read-read back' check involving two nurses being rated the most appropriate. The strong, general support for $\mathrm{DC}$ is connected to the personal experiences reported by the nurses: Depending on the DC scenario

Table 4 Results of logistic regression analysis with dichotomised double-check appropriateness rating as the outcome; model with cluster robust SEs

\begin{tabular}{|c|c|c|c|}
\hline & OR & $95 \% \mathrm{Cl}$ & p Value \\
\hline \multicolumn{4}{|l|}{ Double-check type (to reference 'A') } \\
\hline B & 0.184 & 0.107 to 0.317 & $<0.001$ \\
\hline $\mathrm{C}$ & 0.491 & 0.290 to 0.832 & 0.008 \\
\hline $\mathrm{D}$ & 1.128 & 0.626 to 2.032 & 0.688 \\
\hline$E$ & 2.078 & 1.185 to 3.641 & 0.011 \\
\hline \multicolumn{4}{|l|}{ DC performed at own unit (to reference 'yes, regularly') } \\
\hline Occasionally & 0.211 & 0.126 to 0.354 & $<0.001$ \\
\hline No & 0.058 & 0.035 to 0.096 & $<0.001$ \\
\hline \multicolumn{4}{|c|}{ Essential characteristic of DC (to reference 'two nurses check together') } \\
\hline Repeated single check & 1.683 & 0.915 to 3.096 & 0.094 \\
\hline Two independently & 1.597 & 0.936 to 2.725 & 0.086 \\
\hline Age, years & 1.008 & 0.986 to 1.031 & 0.455 \\
\hline Female gender & 3.183 & 1.363 to 7.432 & 0.007 \\
\hline \multicolumn{4}{|c|}{ Weekly working hours in direct patient care (to reference '<25 hours') } \\
\hline 25 to 40 & 0.601 & 0.348 to 1.037 & 0.067 \\
\hline$>40$ & 0.668 & 0.359 to 1.244 & 0.204 \\
\hline Experienced with barcode scanning & 0.959 & 0.616 to 1.493 & 0.853 \\
\hline Head nurse & 0.574 & 0.234 to 1.405 & 0.224 \\
\hline Working on ward (vs ambulatory infusion unit) & 0.703 & 0.404 to 1.223 & 0.212 \\
\hline Serious medication error in the past 12 months & 0.775 & 0.470 to 1.278 & 0.318 \\
\hline Number of observations & 1190 & & \\
\hline Number of individuals & 248 & & \\
\hline $\mathrm{R}^{2}$ & 0.35 & & \\
\hline Overall model $p$ & & & $<0.001$ \\
\hline
\end{tabular}


presented, between $45 \%$ and $25 \%$ of participants indicated that at least several errors per month had been detected using this method. Thus, in everyday work life, nurses commonly make the experience that inconsistencies are detected with DC. In contrast, inconsistencies not found during checking and the extent of errors which remain invisible but could be found with other checking procedures are not personally experienced. Thus, every 'hit' sends a positive feedback and reinforces the positive attitude towards DC. Our finding that two-thirds of nurses who experienced a recent medication error believed that this error could have been prevented with thorough DC suggests that the selective confirmation of DC may cause a generalisation of its perceived effectiveness.

\section{Preferences towards current practice}

While the variance in appropriateness ratings confirms that participants responded sensitively to the scenario descriptions and adjusted their judgement accordingly, our results also emphasise a 'bias towards the known' with regard to currently practised DC procedures. Whether a certain check was implemented at the unit was a significant independent predictor for a high appropriateness rating. This status quo bias is also expressed in various other survey items: for example, the vast majority of responders indicated that they would not eliminate or change the frequency of specific checks and regarded the extent of checks at their unit as 'just right'. Nurses who currently routinely perform double-checks on premedications strongly supported this procedure, whereas those who currently do not double-check were reserved about introducing this practice. Our results lend support to an Australian study which reported a reluctance to de-implementation of DC among nurses. In this study, nurses held strong views against single-checking before the practice was changed from DC to single-checking. ${ }^{29}$ This preference against change demonstrates the virtual 'inviolability' of the double-check notwithstanding the increasing evidence questioning the effectiveness of currently implemented DC procedures.

\section{Independence of checks}

Our study confirms the qualitative research regarding the variability in interpretations and ideas of what constitutes a double-check, the importance of independence of checks and how it can be achieved. ${ }^{20}{ }^{21}$ Only a quarter regarded the independence of checks as the essential feature of DC, whereas twice as much selected 'doing the checks together'. In scenarios which allow configuration of an independent check (scenarios C-E), only $37-51 \%$ of responders reported that the routine is currently implemented in order to achieve independence (ie, not knowing the results of the co-worker). This points to a structural and prevalent misunderstanding of the rationale behind DC procedures. One basic prerequisite for the redundancy principle to be successful is the independence between redundant 'units.." In technical systems, this requirement is usually satisfied because non-living objects (eg, computers) which serve as a backup for other non-living objects are unaware of each other. Their performance is unaffected by the presence or absence of the redundant unit. In contrast, this principle is typically violated in social systems. Human participants are aware that their co-workers will conduct redundant checks. Independence within the specific check itself can be more or less simulated (eg, by not sharing information as recommended in DC guidelines). ${ }^{12}$ Yet, even simply knowing that a second check will be conducted may negatively affect motivation and result in the tendency to make less effort. The violation of independence can result in greater diffusion of responsibility and thus decreased system safety. ${ }^{14}$ This has been confirmed in qualitative studies, in which nurses indicated that DC would reduce the perceived responsibility of individuals because others would pick up potential mistakes. ${ }^{20} 25$ Oncology nurses in our survey judged the read-read back procedure, a routine which relies on the presence and literal 'dialogue' of two nurses, as most appropriate. These professionals are persistently confronted with administering high-risk drugs to vulnerable patients and the genuine function of DC here may indeed be to share responsibility for safe drug administration. Furthermore, the identified misconception of the independence principle and its importance in combination with the finding that many nurses felt disturbed by environmental factors means that while doing their checks together, nurses are subject to the same environmental impacts, such as insufficient light or noise or interruptions. Consequently, we advocate critically discussing what true independence in DC means and how it can be achieved in clinical practice. Our results also support the proposition to define what is meant by a double-check more precisely. ${ }^{21}$

\section{Potential hazards connected to DC}

Recent analyses of incidents revealed how many collaborative cross-checks failed and did not prevent severe incidents. ${ }^{31}$ On the basis of our findings, we would like to raise awareness about potential hazards that may be connected to DC.

First, our results highlight the interplay between DC and interruptions in workflow: nurses reported frequent interruptions caused by $D C$, particularly at the ambulatory infusion units, and often felt disturbed by interruptions during $D C$. Given the evidence that interruptions in medication-related tasks are strongly associated with errors, this is alarming. ${ }^{32} 33$ On the basis of direct observation of medication administration, Trbovich et $a l^{34}$ reported that nurses in ambulatory infusion units were interrupted $22 \%$ of their time and frequently interrupted during safety-critical stages. Our results confirm that medication administration at ambulatory infusion units may be particularly affected by frequent interruptions. Prakash $e t a l^{35}$ recently investigated the effects of 
interruptions during chemotherapy verification and administration on the frequency of errors. In this study, nurses made significantly more errors in verification of medication volumes in syringes and infusion pumps when interrupted. Taking these studies into account, our results indicate that without reorganising DC routines in clinical practice, the procedure may in fact increase the risk for error.

Second, the strong general support for DC that we observed coexists with frequent violations of important DC rules. A third of responders were aware of at least weekly non-adherence to safety rules at their unit, such as DC medications for different patients in series without a break. Such violations of safety rules undermine the value of DC procedures by limiting its potential effectiveness and promoting a false sense of safety.

Third, a considerable fraction of nurses $(11 \%)$ in our study reported that they did not know the contents of medication administration guidelines at their unit well, and nearly $10 \%$ were unaware whether such guidelines existed. This finding per se is a matter of concern and confirms that even local medical guidelines and safety standards are often not well disseminated and known in practice. It may also suggest that the guidelines in place are not perceived as being usable or helpful for practice. For example, the local guidelines of the participating units we consulted mention DC, but do not provide any details on how checks should be done. Taken together, nurses may receive confirmation and safeguarding during chemotherapy verification from doing checks together and sharing responsibility rather than from complying with (vague) guidelines.

\section{LIMITATIONS}

Our study has some limitations: First, it relies on selfreported practices and experiences and is, as such, subject to various biases. For example, nurses may underestimate or overestimate the true prevalence of DC rule violations or the frequency with which DC detects inconsistencies. Second, to overcome the poor conceptualisation of the umbrella term 'double-check', we prepared descriptions of core subprocesses based on observations in clinical practice. This has the advantage that participants shared a basic common understanding when answering survey questions. On the other hand, specific aspects or steps of DC procedures in the specific units may not have been taken into account in the scenarios or may have lured respondents into a false sense of detail, although we have no indication of this (eg, in the free-text response fields in the survey).

\section{CONCLUSIONS}

Generally, the survey showed that DC is a procedure well supported by nurses working in oncology which, in their experience, helps to detect errors. They used joint DC frequently, preferred this method over others and rated it appropriate to prevent medication errors. These findings show that clinicians' perspectives are not matching current recommendations claiming that checks need to be carried out independently to increase safety. Thus, knowledge about the importance of independence in DC needs to be transferred more actively into clinical practice, so that healthcare professionals implementing and using DC procedures can adopt their procedures accordingly. The high frequency of reported interruptions during, and caused by, DC is a matter of great concern. Existing ideas to reduce interruptions during checking, such as quiet zones, need to be tested in future research.

Acknowledgements The authors thank all nurses who participated in the survey. The support of the clinical experts in providing feedback to the survey and especially of Anna Götz (nursing expert) in survey design and field testing is highly appreciated.

Contributors DLBS, YP and KT contributed to the design of the study and the survey instrument. DLBS analysed the data. YP and KT contributed to the interpretation of data. DLBS wrote the draft. YP and KT provided important intellectual content. All authors approved the manuscript.

Funding This work was supported by a research grant from Krebsforschung Schweiz (Cancer Research Switzerland, KFS-3496-08-2014) and an unrestricted research grant by the Hanela-Stiftung.

\section{Competing interests None declared.}

Ethics approval Cantonal Ethics Committee Zuerich (KEK ZH Nr. 34-2015) on the basis of the Swiss Legislation (Human Research Act, HRA).

Provenance and peer review Not commissioned; externally peer reviewed.

Data sharing statement No additional data are available.

Open Access This is an Open Access article distributed in accordance with the Creative Commons Attribution Non Commercial (CC BY-NC 4.0) license, which permits others to distribute, remix, adapt, build upon this work noncommercially, and license their derivative works on different terms, provided the original work is properly cited and the use is non-commercial. See: http:// creativecommons.org/licenses/by-nc/4.0/

\section{REFERENCES}

1. Schwappach DL, Wernli M. Medication errors in chemotherapy: incidence, types and involvement of patients in prevention. A review of the literature. Eur J Cancer Care 2010;19:285-92.

2. Taylor JA, Winter L, Geyer LJ, et al. Oral outpatient chemotherapy medication errors in children with acute lymphoblastic leukemia. Cancer 2006;107:1400-6.

3. Ford CD, Killebrew J, Fugitt P, et al. Study of medication errors on a community hospital oncology ward. J Oncol Pract 2006;2:149-54.

4. Watts RG, Parsons K. Chemotherapy medication errors in a pediatric cancer treatment center: prospective characterization of error types and frequency and development of a quality improvement initiative to lower the error rate. Pediatr Blood Cancer 2013;60:1320-4.

5. Mattsson TO, Holm B, Michelsen $\mathrm{H}$, et al. Non-intercepted dose errors in prescribing anti-neoplastic treatment: a prospective, comparative cohort study. Ann Oncol 2015;26:981-6.

6. Walsh KE, Dodd KS, Seetharaman K, et al. Medication errors among adults and children with cancer in the outpatient setting. $J$ Clin Oncol 2009;27:891-6.

7. Womer RB, Tracy E, Soo-Hoo W, et al. Multidisciplinary systems approach to chemotherapy safety: rebuilding processes and holding the gains. J Clin Oncol 2002;20:4705-12.

8. Voeffray M, Pannatier A, Stupp R, et al. Effect of computerisation on the quality and safety of chemotherapy prescription. Qual Saf Health Care 2006;15:418-21.

9. Dinning C, Branowicki P, O'Neill JB, et al. Chemotherapy error reduction: a multidisciplinary approach to create templated order sets. J Pediatr Oncol Nurs 2005;22:20-30. 
10. Goldspiel BR, DeChristoforo R, Daniels CE. A continuous-improvement approach for reducing the number of chemotherapy-related medication errors. Am J Health Syst Pharm 2000;57(Suppl 4):S4-9.

11. David BA, Rodriguez A, Marks SW. Risk reduction and systematic error management: standardization of the pediatric chemotherapy process. In: Henriksen K, Battles JB, Keyes MA, Grady ML, eds. Advances in patient safety: new directions and alternative approaches. Rockville: Agency for Healthcare Research and Quality, 2008.

12. Institute for Safe Medication Practices (ISMP). Independent double checks: undervalued and misused. ISMP Medication Safety Alert 18 [12]. 2013.

13. National Patient Safety Agency. Promoting safer use of injectable medicines. Patient Safety Alert 20. 2007.

14. Schöbel M, Manzey D. Subjective theories of organizing and learning from events. Saf Sci 2011;49:47-54.

15. Tamuz M, Harrison MI. Improving patient safety in hospitals: contributions of high-reliability theory and normal accident theory. Health Serv Res 2006;41:1654-76.

16. Alsulami Z, Conroy S, Choonara I. Double checking the administration of medicines: what is the evidence? A systematic review. Arch Dis Child 2012;97:833-7.

17. Ramasamy S, Baysari MT, Lehnbom EC, Westbrook JI, ed. Double-checking medication administration. Evidence Briefings on Interventions to Improve Medication Safety; 1-4 August 2013. Sydney. Sydney: Australian Commission on Safety and Quality in Health, 2013.

18. Kruse $\mathrm{H}$, Johnson $\mathrm{A}$, O'connell $\mathrm{D}$, et al. Administering non-restricted medications in hospital: the implications and cost of using two nurses. Aust Clin Rev 1991:12:77-83.

19. White RE, Trbovich PL, Easty AC, et al. Checking it twice: an evaluation of checklists for detecting medication errors at the bedside using a chemotherapy model. Qual Saf Health Care 2010;19:562-7.

20. Dickinson A, McCall E, Twomey B, et al. Paediatric nurses understanding of the process and procedure of double-checking medications. J Clin Nurs 2010;19:728-35.

21. Hewitt T, Chreim S, Forster A. Double checking: a second look. $J$ Eval Clin Pract 2016;22:267-74.

22. Conroy S, Appleby K, Bostock D, et al. Medication errors in a children's hospital. Paediatr Perinat Drug Ther 2007;8:18-25.
23. Alsulami Z, Choonara I, Conroy S. Paediatric nurses' adherence to the double-checking process during medication administration in a children's hospital: an observational study. J Adv Nurs 2014;70:1404-13.

24. West E. Organisational sources of safety and danger: sociological contributions to the study of adverse events. Qual Health Care 2000:9:120-6.

25. Armitage G. Double checking medicines: defence against error or contributory factor? J Eval Clin Pract 2008;14:513-19.

26. Kloth DD. Prevention of chemotherapy medication errors. J Pharm Pract 2002;15:17-31.

27. Jacobson JO, Polovich M, McNiff KK, et al. American Society of Clinical Oncology/Oncology Nursing Society Chemotherapy Administration Safety Standards. Oncol Nurs Forum 2009;36: 651-8.

28. Onkologiepflege Schweiz. Nationale standards: verabreichung der chemotherapie. Leitfaden für die Praxis. Bern: Onkologiepflege Schweiz, 2008.

29. O'Connell B, Crawford S, Tull A, et al. Nurses' attitudes to single checking medications: before and after its use. Int J Nurs Pract 2007:13:377-82.

30. Sagan SD. The problem of redundancy problem: why more nuclear security forces may produce less nuclear security. Risk Anal 2004;24:935-46.

31. Patterson ES, Woods DD, Cook RI, et al. Collaborative cross-checking to enhance resilience. Cognit Technol Work 2007;9:155-62.

32. Rivera-Rodriguez AJ, Karsh BT. Interruptions and distractions in healthcare: review and reappraisal. Qual Saf Health Care 2010;19:304-12.

33. Westbrook Jl, Woods A, Rob Ml, et al. Association of interruptions with an increased risk and severity of medication administration errors. Arch Intern Med 2010;170:683-90.

34. Trbovich P, Prakash V, Stewart J, et al. Interruptions during the delivery of high-risk medications. J Nurs Adm 2010;40:211-18.

35. Prakash V, Koczmara C, Savage P, et al. Mitigating errors caused by interruptions during medication verification and administration: interventions in a simulated ambulatory chemotherapy setting. BMJ Qual Saf 2014;23:884-92. 